\title{
The Process Of Macroeconomic Decision Making In Democratic And Dictatorial Countries
}

\author{
Reza Fadaei, National University, USA \\ Gao Feng, Nanfang College of Sun Yat-Sen University, China
}

\begin{abstract}
Real-world problems are usually complicated by many interrelated factors. It is, however, difficult to distinguish between symptoms and problems. To facilitate approaches to problem solving, we must study the organization's input, processes, and outputs. Measuring of productivity, as well as the construction of models, is based upon data and government information. The questions we would like to address in this paper is how the decision making process might take place in developed countries versus how it might take place in underdeveloped countries, and how it might take place in democratic countries versus how it might take place in dictatorial countries?
\end{abstract}

Keywords: Decision Making in Democratic Countries; Decision Making in Dictatorial Countries; Macroeconomic Decision Making

\section{INTRODUCTION}

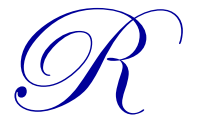

eal-world problems are often complicated by many interrelated factors making it difficult to distinguish between symptoms and problems. To make a distinction between these two requires an analysis of various forms of data, an adequate time allotment, a subjective focus, and a careful prediction of future conditions. From a Management Science perspective, these decision categories will revolve around three poles: Certainty, Risk, and Unpredictability.

First, decisions made where the outcome is certain naturally assume that complete information is available so that the decision maker knows exactly the outcome of each course of action will be, for example, the alternatives to investing in U.S. Saving Bonds is deterministic.

Secondly, decision making under risk or probabilistic conditions is very similar to the processes employed in investing in stocks and may result in a positive annual rate of return on investment or a negative annual rate of return, depending on parameters inherent in the economy.

Thirdly, decision making under unpredictable conditions will look very similar to decision making where several outcomes may be possible for each course of action. The decision maker does not know, or cannot predict the ultimate outcome of the decision tree, and so it may be impossible to assess the outcome of decisions made under unpredictable conditions.

Thus, unpredictable conditions contain less information than risky conditions. Business leaders who wish to make beneficial decisions must be careful to very clearly identify problems and ascertain relevant details to be investigated in order to clearly identify unresolved issues relevant to the solution of problems. For example, these business leaders should know how to gather data necessary to draw appropriate conclusions and implement effectively the results of this process as a way to solve problems. While this behavior is at the core of business research, it will be vastly augmented by careful employment of quantitative methods and statistics. 
In business research, therefore, it is important to employ a careful and thoughtful approach toward examining the underlying processes inherent in a business operation before making predictions about solutions. The purpose of business research then is to resolve most of the difficult questions related to production, finance, accounting, and marketing which in the long have the greatest probability to increase the level of the GDP.

While this approach is an efficient way to test a new proposition or a new concept, quantitative business research is also useful in measuring and analyzing trends, product consumption, product use, and other aspects of production which require mathematical precision. In the process of making this analysis, data collection could occur through observational surveys, such as a survey about individual movements, work habits, assertions and so on. In meeting demand in a fast changing business environment, then, it is important to identify problems first, and only then deal with symptoms before they occur. A research conclusion, then, is a tool business leaders use to troubleshoot problems in organizations in order to take corrective measures before situations get out of control.

\section{WHO ARE THE DECISION MAKERS IN DEMOCRATIC VERSUS DICTATORIAL COUNTRIES?}

The United States of America is an example of a democratic country with a free market economy, as are Germany, Japan, France, and several other similar countries around the world. Democratic free market countries provide possibilities for its citizens. In these industrialized economies, many opportunities exist for its citizens and residents to work up the class hierarchy out of poverty, perhaps to become wealthy. We predict that economic growth numbers in these countries will be greater every year. As people in these countries are allowed to become deeply involved in this economic growth and are allowed to share in this growth, it is important to remember that decision makers are also a key part of this growth.

In dictatorial countries, only government makes decisions. In the long run this exclusivity may bring about the possibility of corruption in key positions and may lead to economic downturns along with other problems. Countries such as North Korea, Iran, Pakistan, may be considered to be dictatorial. Since decision making is not shared and since their citizens are not deeply involved in the process of creating economic growth, possibilities for average citizens to work up the class hierarchy out of poverty, perhaps to become wealthy, are limited if nonexistent. As a consequent to this, citizens of dictatorial countries may often feel that they do not have hope for the future or hope for their nation. In the dictatorial country, because decision making and economic growth is not shared, opportunities for their citizens to get ahead are limited. There is no way to work your way out of poverty. In the dictatorial countries if you are born a peasant, you will most likely die a peasant. In addition, in dictatorial countries, job opportunities are not as present as in the democratic countries. And so, since government is the decision maker, checks and balances to prevent corruption are not as present as in democratic countries, leaving the impression that the government takes from their people rather than benefits. For example, Iran has huge resources but produces nearly no exportable output. This is also the situation for North Korea, many countries in the Middle East, and for a few South American countries.

It is, of course, true that countries do operate differently and so have completely different rates of economic growth. The style of government affects its economic situation and outlook. Consequently, North Korea relies heavily on foreign aid to feed its people. It is tempting to expand this conclusion not only to North Korea, but to all the dictatorial countries around the world. In stark contrast to the uncertainty and clear economic unpredictability of North Korea, Saudi Arabia, a non-democratic country founded in 1932 by Ibn Saud, and with the discovery by American geologists of one of the largest provable reserves of petroleum in global history, has become an economic powerhouse. Yet, Saudi Arabian women are not allowed to travel without a guardian; are not allowed to vote, drive, or play sports.

Economic growth of a country can be measured by Gross Domestic Product or GDP. If we study each of the gauges of economic growth, an educated opinion may be formed regarding the economic growth possibilities of particular country. One fact to bear in mind in executing this study due in a dictatorial country is that corruption may often be the reason why a dictatorial country's financial data is closely guarded and not available to study. North Korea has a difficult financial situation due to the country's nature of "self-reliance" also involving close guarding of financial data. This attitude discourages trade and other types of business ventures that may benefit its citizens. For this reason, accurate economic figures are difficult to obtain for North Korea. Other methods are therefore being 
employed to determine the state of its economy. "North Koreans now face the threat of starvation, malnourishment remains a widespread problem as many (perhaps, a majority of) North Koreans don't have enough to eat in spring" (Lankov, 2011).

This bleak situation has had a seriously negative impact on the health of North Koreans, especially for North Korean children. Fortunately, unlike that of the 1990s, the North Korean situation is now not as dire. The average North Korean meal is a bowl of boiled corn with a few pickles. Meat or fish are eaten only on special occasions or by the affluent (Lankov, 2011). Over the last decade in North Korea, material inequality has greatly increased. Some of the new North Korean rich are officials who have taken advantage of their positions. Others are successful entrepreneurs running all kinds of private businesses. This is a welcome sign for this once very bleak dictatorship.

The latest estimated GDP in North Korea is $\$ 28$ billion US dollars with a real growth rate of $4 \%$ in 2011. In comparison to the rest of the world they are ranked $98^{\text {th }}$, with a $-0.4 \%$ for 2010 , and $-0.9 \%$ for 2009 (Factbook, 2012). In contrast, Japan is one of the leading countries in the economic sector. Their automobile manufacturing is the third largest in the world and they are ranked number one in the electronic goods industry according to IMF. Japan is also one of the most innovative countries. One of the major factors for Japanese productivity is its democratic form of government. Japanese people are their own decision makers, not the Japanese government. Consequent non-existent government corruption and monetary freedom are possible explained by democratic decisions in the management of government spending along with labor freedom that is a hallmark of most democratic governments (Heritage.org).

Germany is one of the super powers of the world with advanced technological, informational, political, and social infrastructure. Germany is influential in the European political arena, and also in various industries. It has a democratic government that keeps spending under control.

Therefore, dictatorship, mismanagement, and corruption are clearly related to a country's economic success and also are part of the reasons for an abrupt and sometimes violent end.

\section{SUMMARY AND CONCLUSION}

The world economy is a stage with many different performers affected by its vagaries. Recent slowing in economic progress has been a challenge inevitably faced by both developed and underdeveloped countries. However, when we study organizational input, processes, and output, organizations located in countries that are vastly different in the scale of their economies can still perform similarly. We hope to have demonstrated that this may partially be explained because of economic freedom within that country and because of a democratic form of government. However, countries with abundant natural resources, but mismanagement, dictatorship, and corruption do not seem to share the same economic success. On the contrary, they exhibit often an abrupt and sometimes violent end. Therefore, we have hoped to show that there is no other fundamental solution to bringing about organizational success in a dictatorial country other than to change from dictatorship to democracy.

\section{AUTHOR INFORMATION}

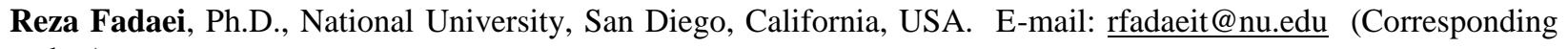
author)

Gao Feng, Nanfang College of Sun Yat-Sen University, Gao Feng, Nanfang College of Sun Yat-Sen University, Guangzhou, China. E-mail: 2284791181@qq.com

\section{REFERENCES}

1. Backer, G. (1964). Human capital. New York: National Bureau of Economic Research.

2. Dictatorship. (n.d.). Merriam-Webster online. Retrieved December 23, 2012, from http:// www.merriamwebster.com//dictionary/dictatorship 
3. Donnelly, J. NPC, Freedom House plan annual survey release on world Press Freedom Day. Retrieved from http: //www.press.org/news-multimedia/news/npc-freedom-house-present-annual-survey-worldwidepress-freedom

4. Economist Intelligence Unit. (2011). Country by country forecast of political and economic trends in over 180 countries. United Kingdom.

5. Harrisona, R.T. \& Mason, C.M. (2008 October). Sampling and data collection in business angel research. Retrieved from Ebsco Host.

6. International Monetary Fund. (2009). World economic outlook. IMF Multimedia Services Division.

7. Lankov, A. The North Korean economy: Between myths and facts. Retrieved December 23, 2011 from: http//www.eastaside forum.org/ 2011/02/08/ the-North-Korean- economy-between-mths-and-facts

8. (n.d.). Retrieved from http://www.bls.gov/fls/Japan.htm

9. (n.d.). Retrieved from http://www.bls.gov/fls/mexico.htm

10. Sekaran, U. (2003). Research methods for business ( $4^{\text {th }}$ ed.). John Wiley \& Sons, Inc.

11. The Heritage Foundation. (n.d.). Retrieved from http://www.heritage.org/Index/Country/ Germany 